\title{
Application of remifentanil combined with propofol in the diagnosis of colon cancer with awakening painless digestive endoscopy
}

\author{
AILAN XIAN $^{1 *}$, CHUNBIN WANG $^{2 *}$, NI GUO $^{1}$, ZAIXING WANG $^{3}$, \\ LEI YANG ${ }^{1}$, JIE GAO $^{1}$ and LONGJUN YANG ${ }^{4}$ \\ Departments of ${ }^{1}$ Gastroenterology and ${ }^{2}$ Pharmacy, Dongying People's Hospital, \\ Dongying, Shandong 257091; ${ }^{3}$ Department of Gastroenterology, The People's Hospital of Guangrao, \\ Dongying, Shandong 257300; ${ }^{4}$ Department of Anesthesiology, Dongying People's Hospital, \\ Dongying, Shandong 257091, P.R. China
}

Received May 23, 2018; Accepted November 22, 2018

DOI: $10.3892 / 01.2018 .9801$

\begin{abstract}
Anesthetic effect of remifentanil combined with propofol in awakening painless endoscopy was analyzed. Retrospective analysis of 120 cases of colon cancer were treated in Dongying People's Hospital from June 2015 to December 2017. All of them were treated by awakening painless digestive endoscopy, divided into 60 cases in observation group (combined with remifentanil and propofol anesthesia), and 60 cases in control group (combined intravenous anesthesia of finanib and propofol). The data were respectively recorded at time-points of oxygen inhalation, intubation for $10 \mathrm{~min}$, awakening time, waking time, and the time-points for each represented as the time-points of T1, T2, T3, T4, T5 and recorded the diastolic blood pressure (DBP), respiratory rate (RR) and heart rate (HR), and compared the awakening effect and the occurrence of adverse reaction. There was no significant difference in the DBP index between the two groups at time-point $\mathrm{T} 1(\mathrm{P}>0.05)$. The time-points of $\mathrm{T} 2, \mathrm{~T} 3$, T4 and T5 were significantly different from the observation group $(\mathrm{P}<0.05)$. There was no significant difference in $\mathrm{RR}$ index between the two groups and between the same groups ( $>0.05)$. Compared with the control group, the awakening time and consciousness recovering of the observation group is lower $(\mathrm{P}<0.05)$. The incidence of adverse reactions after awakening operation between the two groups was statistically significant $(\mathrm{P}<0.05)$. The local pain rate in the observation
\end{abstract}

Correspondence to: Dr Longjun Yang, Department of Anesthesiology, Dongying People's Hospital, 317 Nanyi Road, Dongying, Shandong 257091, P.R. China

E-mail: y7c3wr@163.com

*Contributed equally

Key words: remifentanil, fentanyl, propofol, digestive endoscopy, colon cancer group after the awakening operation was lower than the control group. The combined use of trace remifentanil and small dose propofol in the awakening painless digestive endoscopy can make the patients with colon cancer more stable when they are in the awakening state, so as to improve the safety of awakening painless digestive endoscopy. It is worth promoting in clinical practice.

\section{Introduction}

Colon cancer is a high incidence digestive tract malignant tumor in China, second only to stomach, esophagus and large intestine cancer. It is the fourth place of gastrointestinal malignant tumors. In recent years, the incidence of the cancer is increasing year by year, and its incidence is higher in some developed countries. Most people suffering from colon cancer are male, aged 40-50-years, but in recent years there has been a trend towards younger males (1). According to the data of research by Benson et al (2), the incidence of colon cancer is increasing each year with the development of modern social economy, and the change of dietary and life habits.

Digestive endoscopy is the most commonly used method for clinical diagnosis of colon cancer. In recent years, it has been widely used to maturing the awakening of painless digestive endoscopy (3). By using head nerve blocking, it can carry out meticulous and awakening anesthesia depth management for awakening painless digestive endoscopy technology (4). The awakening painless digestive endoscopy relieves the psychological fear and discomfort caused by common endoscopic diagnosis and treatment, and improves the accuracy of the general endoscopic diagnosis and treatment, and the awakening technique can reduce the adverse reactions and complications in the diagnosis and treatment. It is a high clinical value of anesthesia (5).

At present, fentanyl combined with propofol can be used as an anesthetic drug by awakening painless digestive endoscopy, but according to the study of Pearlman et al (6), there are more adverse reactions (such as dizziness, nausea, vomiting and irritability) and even respiratory depression. 
Remifentanil is a new type of mu receptor agonist. It has the advantages of quick onset, side-effects lasting for short time, and easy control of intravenous infusion (7). Therefore, remifentanil combined with propofol can be widely used as an anesthetic drug (8). To analyze and compare the anesthetic and awakening effect of remifentanil combined with propofol in the painless endoscopic diagnosis and treatment, the anesthetic and awakening effects of fentanyl combined with propofol were compared and analyzed. This study was used to evaluate the efficacy and safety of remifentanil combined with propofol in the diagnosis and treatment of colon cancer patients, and to provide reference and guidance for the clinical use of awakening technique in the diagnosis and treatment for colon cancer.

\section{Patients and methods}

Clinical data. A total of 120 cases of colon cancer were diagnosed and treated with the awakening painless digestive endoscopy from June 2015 to December 2017, of which 60 cases of remifentanil combined with propofol were the observation group and 60 cases of fentanyl combined with propofol anesthesia were the control group. In the observation group, there were 23 female patients, 37 male patients, aged 35-76 years, the average age was $49.7 \pm 6.3$ years, with a body weight of $51-86 \mathrm{~kg}$, and an average body weight of $61.7 \pm 3.2 \mathrm{~kg}$. In the control group, there were 26 female patients, 34 male patients,

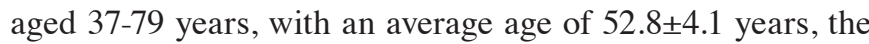
body weight of $48-86 \mathrm{~kg}$, and an average body weight of $63.5 \pm 4.8 \mathrm{~kg}$. There was no significant difference $(\mathrm{P}>0.05)$, indicating that the two groups were statistically significant and comparable (Table I). The study was approved by the Ethics Committee of Dongying People' s Hospital (Dongying, China). Signed informed consents were obtained from the patients or the guardians.

Inclusion and exclusion criteria. The pathological sections and clinical manifestation of the selected cases were all consistent with colon cancer manifestations. Patients who had not received related diagnosis and treatment in other hospitals and who did not cooperate with the examination, were excluded. Patients with allergic reaction or contraindication of anaesthetic drugs used in the study, in pregnancy and lactation period, suffering from acute gastrointestinal bleeding or other serious diseases, with communication disorders and cognitive impairment and with contraindication of digestive endoscopy, were excluded. All the subjects or their families signed the informed consent and completed the relevant diagnosis and treatment with the medical staff.

Inspection methods. The patients were in water prohibition before the awakening painless digestive endoscopy for first $8 \mathrm{~h}$, and the ProSim 8 monitor of the Fluke Corp., (Everett, WA, USA) was used in treatment room, and the time-points were detected after the intubation of the patients, respectively. Before oxygen inhalation (T1), intubation for $10 \mathrm{~min}$ (T2), awakening time (T3), waking time (T), and extubation (T5), the diastolic blood pressure (DBP), respiratory rate (RR) and heart rate $(\mathrm{HR})$ were recorded at these time-points, and the incidence of adverse reactions after wake-up operation and the effect of awakening were compared and analyzed in the two groups.

The patients in the observation group were treated with remifentanil (Yichang Renfu Pharmaceutical Co., Ltd., Yichang, China; batch no. H20030197) combined with propofol (Bachem SA, Vionnaz, Switzerland; batch no. H20120308) all intravenous anesthetic treatment, infusion of remifentanil $0.10-0.12 \mathrm{~g} /(\mathrm{kg} \cdot \mathrm{min})$, and slow injection of propofol $0.5-1.0 \mathrm{mg} /(\mathrm{kg} \cdot \mathrm{h})$, pump injection rate according to the patient's HR, blood pressure and so on, and then routinely using nasal catheter oxygen inhalation $4 \mathrm{l} / \mathrm{min}$, until the end of the diagnosis and treatment. Patients in the control group were given compound fentanyl (Yichang Renfu Pharmaceutical Co., Ltd.; batch no. H42022076) and propofol intravenous anesthesia were diposed by intravenous infusion of fentanyl $0.5 \mu \mathrm{g} /(\mathrm{kg} \cdot \mathrm{min})$, and propofol $1.0 \mathrm{mg} /(\mathrm{kg} \cdot \mathrm{h})$ diluted with a complex concentration of $5 \%$ glucose saline. The pump rate and propofol dosage were added and reduced according to the patient's HR, blood pressure, and then routinely using the nasal catheter to breathe $4 \mathrm{l} / \mathrm{min}$, straight until the end of the diagnosis and treatment.

Statistical analysis. The IBM Corp., 19.1, (Armonk, NY, USA) software system was used to carry out statistical analysis, in which the enumeration data are expressed by percentage [n (\%)], and the difference between the two groups was compared with $\chi^{2}$ test. Measurement data are expressed by mean $\pm \mathrm{SD}$, and t-test was used to compare the difference between the two groups. Analysis of variance (ANOVA) with least significant difference test was used to compare each time-point in the group. The difference is statistically significant $(\mathrm{P}<0.05)$.

\section{Results}

The analysis of DBP indexes in the observation and control group at each time-point. The time-points of T1, T2, T3, T4, and $\mathrm{T} 5$ in the observation group were $90.42 \pm 7.47,89.81 \pm 5.20$, $88.58 \pm 6.14,87.96 \pm 8.21$, and $89.76 \pm 7.47 \mathrm{mmHg}$, and the control group were $91.27 \pm 8.37,87.64 \pm 6.92,84.32 \pm 5.16$, $90.67 \pm 4.47$, and $92.38 \pm 6.42 \mathrm{mmHg}$. There was no significant difference in DBP index between the control and the observation group at time-point $\mathrm{T} 1(\mathrm{P}>0.05)$. The time-points of $\mathrm{T} 2$, $\mathrm{T} 3$, T4 and T5 were significantly different from the observation group $(\mathrm{P}<0.05)$. There was no significant change in $\mathrm{DBP}$ index in the observation group at each time-point $(\mathrm{P}>0.05)$. But the DBP index of the control group of patients at the time-point of T2, T3 and the previous time-point decreased, and the DBP index at time-point T4 significantly increased, the difference was statistically significant $(\mathrm{P}<0.05)$, there was no significance at time-point $\mathrm{T} 5$ and the previous time-point ( $\mathrm{P}>0.05$ ) (Fig. 1).

The analysis of $R R$ indexes of the observation and control group at each time-point. The time-points of T1, T2, T3, T4 and $\mathrm{T} 5$ in the observation group were $28.73 \pm 1.31,28.58 \pm 1.76$, $29.32 \pm 1.46,28.81 \pm 1.81$, and $28.56 \pm 1.75 \mathrm{times} / \mathrm{min}$, and in the control group were $28.31 \pm 1.17,28.63 \pm 1.56,28.88 \pm 1.63$, $28.55 \pm 0.79,28.62 \pm 1.53$ times $/ \mathrm{min}$. There was no significant 
Table I. The clinical data of 120 cases of colon cancer [n (\%)].

\begin{tabular}{|c|c|c|c|c|}
\hline \multirow[b]{2}{*}{ Variables } & \multicolumn{2}{|c|}{ Groups } & \multirow[b]{2}{*}{$\chi^{2}$} & \multirow[b]{2}{*}{ P-value } \\
\hline & $\begin{array}{c}\text { Observation } \\
\quad(n=60)\end{array}$ & $\begin{array}{r}\text { Control } \\
(\mathrm{n}=60)\end{array}$ & & \\
\hline Sex & & & 0.310 & 0.577 \\
\hline Male & $37(61.67)$ & $34(56.67)$ & & \\
\hline Female & $23(38.33)$ & $26(43.33)$ & & \\
\hline Age (years) & & & 0.196 & 0.658 \\
\hline$<50$ & $12(20.00)$ & $14(23.33)$ & & \\
\hline$\geq 50$ & $48(80.00)$ & $46(76.67)$ & & \\
\hline Drinking or not drinking & & & 0.324 & 0.570 \\
\hline Not drinking & $8(13.33)$ & $6(10.00)$ & & \\
\hline Drinking & $52(86.67)$ & $54(90.00)$ & & \\
\hline Taste preference & & & 0.342 & 0.559 \\
\hline Light & $18(30.0)$ & $21(35.00)$ & & \\
\hline Fat and greasy & $42(70.0)$ & $39(65.00)$ & & \\
\hline Type of pathological diagnosis & & & 0.391 & 0.532 \\
\hline Adenocarcinoma & $46(76.67)$ & $43(71.67)$ & & \\
\hline Mucous adenocarcinoma & $14(23.33)$ & $17(28.33)$ & & \\
\hline Form & & & 0.342 & 0.559 \\
\hline Polypoid & $39(65.00)$ & $42(70.00)$ & & \\
\hline Ulcerative type & $21(35.00)$ & $18(30.00)$ & & \\
\hline
\end{tabular}

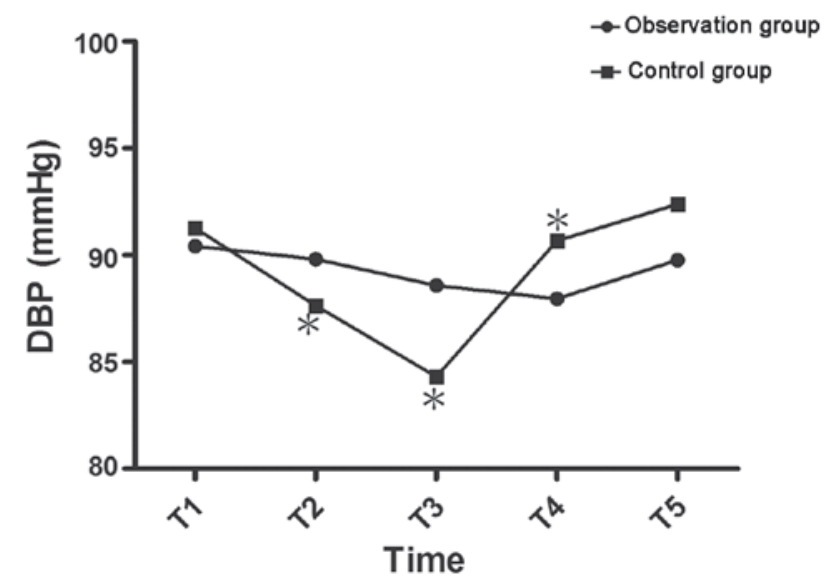

Figure 1. DBP indexes at the time-points of the observation and control group. There was no significant change in DBP index in the observation group at each time-point, and there was no significant difference in the time-points between the two groups $(\mathrm{P}>0.05)$. But there was significant difference between the control and the observation group at the time-points of T2, T3, T4, T5 $(\mathrm{P}<0.05)$, and the DBP indexes of the control group were statistically significant at the time-points of $\mathrm{T} 2, \mathrm{~T} 3, \mathrm{~T} 4(\mathrm{P}<0.05)$. ${ }^{*} \mathrm{P}<0.05$, compared to the previous time-point. DBP, diastolic blood pressure.

difference in RR index between the two groups ( $\mathrm{P}>0.05)$, and there was no significant difference between the same groups at each time-point $(\mathrm{P}>0.05)$ (Fig. 2).

The analysis of HR indexes of the observation and control group at each time-point. The time-points of T1, T2, T3, T4 and $\mathrm{T} 5$ in the observation group were $77.56 \pm 11.25,76.83 \pm 10.68$,

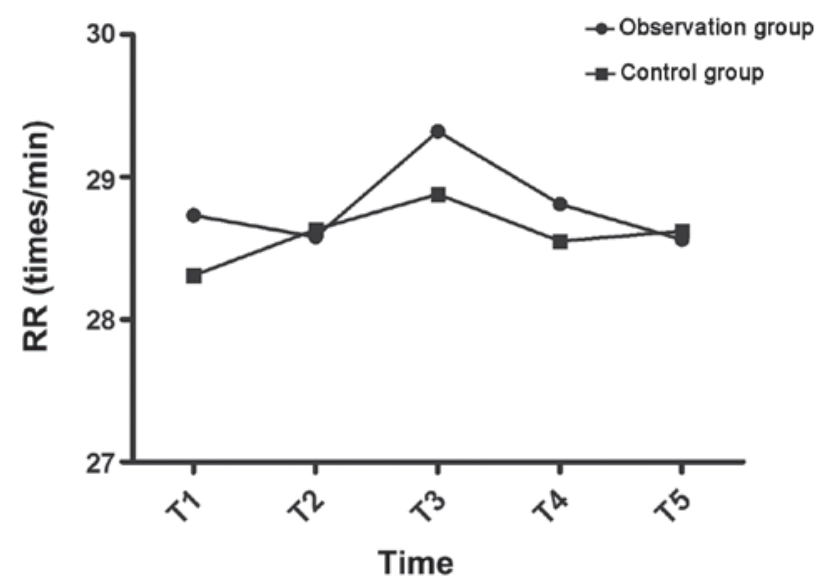

Figure 2. The RR indexes of the observation and control group at each time-point. There was no significant difference in RR index between the two groups $(\mathrm{P}>0.05)$, and there was no significant difference between the same groups at each time-point $(\mathrm{P}>0.05)$. $\mathrm{RR}$, respiratory rate.

$75.45 \pm 11.81,75.92 \pm 10.79$, and $77.16 \pm 10.17 \mathrm{times} / \mathrm{min}$, and the control group were $78.18 \pm 12.62,72.83 \pm 5.68,71.54 \pm 7.36$, $71.84 \pm 10.81,79.73 \pm 5.93$ times $/ \mathrm{min}$. Compared with the observation group, the HR indexes of the time-points of T2, T3 and T4 in the control group were significantly different from the observation group $(\mathrm{P}<0.05)$. The HR indexes of the observation group at each time-point did not fluctuate significantly, the difference was not statistically significant $(\mathrm{P}>0.05)$.There was a significant difference for the control group at the time-points of T2 and T5 and the previous 


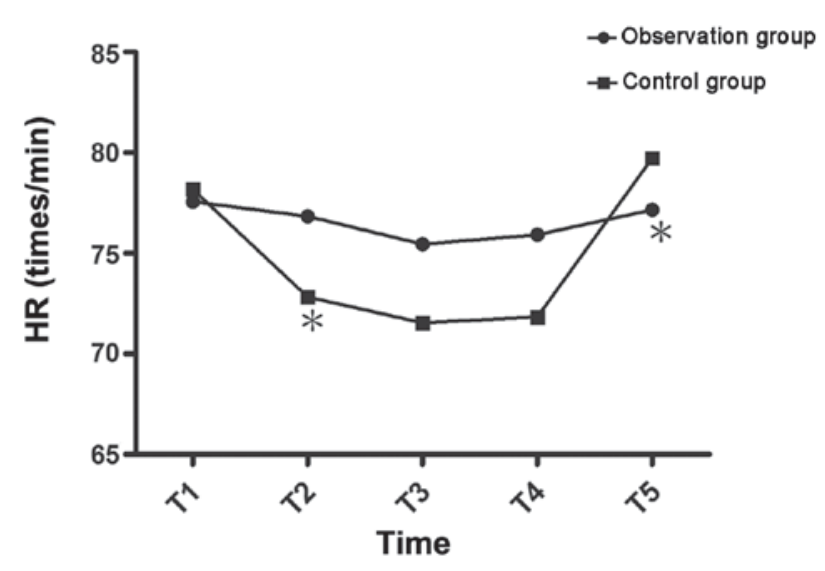

Figure 3. The HR indexes of the observation and control group at each time-point. There was no significant change in HR index in the observation group at each time-point $(\mathrm{P}>0.05)$. But there was significant difference between the control and the observation group at the time-points of T2, T3, $\mathrm{T} 4(\mathrm{P}<0.05)$. The difference between the time-points of T2 and T5 in the control group was statistically significant $(\mathrm{P}<0.05)$. ${ }^{*} \mathrm{P}<0.05$, compared to the previous time-point. HR, heart rate.

time-point $(\mathrm{P}<0.05)$. The difference at the time-point $\mathrm{T} 3$ and the previous time-point was lower and at time-point $\mathrm{T} 4$ was higher, but the difference was not statistically significant (P>0.05) (Fig. 3).

The incidence of adverse reactions and local pain after awakening in the observation and control group. In the observation group, there were 2 cases of dizziness and headache after awakening operation, 1 case of nausea and vomiting, and the incidence of adverse reactions was 5\% (3/60). In the control group, there were 4 cases of dizziness and headache after awakening operation, 5 cases of nausea and vomiting, 2 cases of irritability, and the incidence of adverse reactions was $18.33 \%$ (11/60). The incidence of adverse reactions after awakening operation between the two groups was statistically significant $(\mathrm{P}<0.05)$. There were 5 cases $(8.33 \%)$ of local pain after awakening surgery in the observation group, which was significantly lower than the control group 18 (30\%). There was a significant difference in the incidence of local pain after awakening operation between the observation and control group $(\mathrm{P}<0.05)$ (Table II).

The analysis of the awakening effect of the observation and control group. The time of awakening for $8.68 \pm 4.21 \mathrm{~min}$ and recovery awareness for $12.51 \pm 3.19 \mathrm{~min}$ after wake-up operation was significantly shorter than the control group $(10.14 \pm 3.57$, $13.92 \pm 2.84 \mathrm{~min}$ ), and there was a significant difference in the awakening effect between the observation and control group $(\mathrm{P}<0.05)$ (Table III).

\section{Discussion}

Colon cancer patients may not have any symptoms at the early stage, resulting in high misdiagnosis rate and difficulty in early diagnosis (9). At present, the clinical diagnosis and treatment of colon cancer patients highly recommend digestive endoscopy treatment, and the effective rate is up to $71.34 \%$ (10). In the process of digestive endoscopy, the choice of anaesthetic
Table II. The incidence of adverse reactions and local injection pain in the two groups of patients after awakening [n (\%)].

\begin{tabular}{lcccc}
\hline & \multicolumn{2}{c}{ Groups } & & \\
\cline { 2 - 4 } Variables & $\begin{array}{c}\text { Observation } \\
(\mathrm{n}=60)\end{array}$ & $\begin{array}{c}\text { Control } \\
(\mathrm{n}=60)\end{array}$ & $\chi^{2}$ & P-value \\
\hline $\begin{array}{l}\text { Incidence of } \\
\text { adverse reaction rate }\end{array}$ & $3(5.00)$ & $11(18.33)$ & 5.175 & 0.023 \\
$\begin{array}{l}\text { Incidence of } \\
\text { local pain }\end{array}$ & $5(8.33)$ & $18(30.00)$ & 10.570 & 0.001 \\
\hline
\end{tabular}

Table III. Time for awakening and recovery of consciousness (min).

\begin{tabular}{|c|c|c|c|c|}
\hline \multirow[b]{2}{*}{ Variables } & \multicolumn{2}{|c|}{ Groups } & \multirow[b]{2}{*}{$\mathrm{t}$} & \multirow[b]{2}{*}{ P-value } \\
\hline & $\begin{array}{l}\text { Observation } \\
\quad(\mathrm{n}=60)\end{array}$ & $\begin{array}{l}\text { Control } \\
(\mathrm{n}=60)\end{array}$ & & \\
\hline Awakening time & $8.68 \pm 4.21$ & $10.14 \pm 3.57$ & 2.05 & 0.04 \\
\hline $\begin{array}{l}\text { Recovery of } \\
\text { consciousness after } \\
\text { awakening operation }\end{array}$ & $12.51 \pm 3.19$ & $13.92 \pm 2.84$ & 2.557 & 0.01 \\
\hline
\end{tabular}

drugs is the key to improve the rate of colon cancer diagnosis and reduce the pain of patients.

In the process of digestive endoscopy, in order to avoid the negative effects of anaesthetic drugs, early pathological changes can be used in the awakening operation of endoscopic minimally invasive technique. If the patient has respiratory depression in the operation, the patient can make deep breathing (11). When the patient changes the body position, the patient can also cooperate, which can reduce the risk of anesthesia and relieve the medical care. The burden of moving is shortened, the operation time is shortened, and the efficiency is increased (12). The anesthetic drugs of awakening digestive endoscopy are mostly propofol, while propofol has a fast metabolism, and the analgesic effect of propofol alone is not good, and the increasing of the dose will cause various signs of unstability (13). Therefore, fentanyl combined with propofol intravenous anesthesia can be used in awakening painless endoscopic diagnosis as treatment. Although fentanyl has a good analgesic effect, it can cause the patients to awake for a long time, short effect of analgesia, respiratory depression, circulation and so on (14). According to the study of Porter-Stransky et al (15), remifentanil hydrochloride is a micron short acting opioid receptor agonist. The analgesic and sedative effect of the compound small dose propofol is better, and the drug dependence and respiratory inhibition rate is lower than fentanyl. The characteristics of remifentanil make it easy to hydrolyze by non-specific esterase and achieve rapid blood-brain balance. In addition, remifentanil is less dependent on kidney and liver metabolism, and avoiding accumulation in body (16). Therefore, it is the key to choose anesthetic methods with fewer adverse reactions and rapid recovery after awakening operation. 
Our study showed that the HR indexes of the observation and control group were statistically significant $(\mathrm{P}<0.05)$ at the time-points of T2, T3, T4 and T5 in the indexes and the time-points of T2, T3, and T4 in the DBP index, but there was no statistical significance $(\mathrm{P}>0.05)$ in the observation group, but the differences in some time-points in the control group were statistically significant $(\mathrm{P}<0.05)$, and it is shown that the control group had a significant difference $(\mathrm{P}<0.05)$. Compared with fentanyl and propofol, remifentanil combined with propofol can stabilize the patients. According to the study of Dumans-Nizard et al (17), DBP, RR and HR have similar results. The time of awakening for $8.68 \pm 4.21 \mathrm{~min}$ and recovery consciousness for $12.51 \pm 3.19$ min after awakening operation in the observation group was significantly shorter than the control group $(10.14 \pm 3.57,13.92 \pm 2.84 \mathrm{~min})$, and the difference of the awakening effect between the two groups was statistically significant $(\mathrm{P}<0.05)$. According to the study of Weiniger et al (18), the characteristics of the pharmacokinetics of fentanyl lead to the instability of the life index, the effect of awakening and the unideal time, while remifentanil can be adjusted to dose accurately according to the efficacy of the drug. The effect can be predicted, the anesthesia is stable and easy to be reversed. In the analysis of awakening operation, there were 3 cases with incidence of adverse reactions after awakening operation in the observation group. In the control group, there were 11 cases with incidence of adverse reactions after awakening operation. The incidence of adverse reactions after awakening operation between the two groups was statistically significant $(\mathrm{P}<0.05)$. After awakening operation, there were 5 cases of local pain in the observation group, which was significantly lower than the control group (16 cases). The difference between the two groups was statistically significant $(\mathrm{P}<0.05)$. The results of this study are consistent with the findings of Aaronson et al (19). Remifentanil combined with propofol anesthesia is safer and more compliant than fentanyl combined propofol anesthesia for patients, and maintain a wakeable state in the process of diagnosis and treatment (20). It is the key to improve the comfort of the patients, short awakening time, and has good quality of awakening after the awakening operation, and the choice of the most suitable anesthetic medication is the key. Remifentanil combined with propofol anesthesia can be used as a better anesthesia option for painless endoscopic surgery. It is worthy of clinical application.

In this experiment, because of the limited medical resources in Dongying People's Hospital, the case number of the selected research subjects is small. It may result in a certain chance, and does not exclude the difference in the response to the anaesthesia after different sex or age. We will carry out a longer tracking survey on the patients of this study to improve our experiments to achieve the best experimental results.

In summary, remifentanil combined with propofol is more effective than fentanyl combined propofol anesthesia to stabilize the patient's vital signs, and improve the safety, and the effect of awakening and postoperative recovery. It is more suitable for the patients with colon cancer by awakening painless digestive endoscopy, and should be popularized in the clinic.

\section{Acknowledgements}

Not applicable.

\section{Funding}

No funding was received.

\section{Availability of data and materials}

The datasets used and/or analyzed during the present study are available from the corresponding author on reasonable request.

\section{Authors' contributions}

AX and CW drafted the manuscript. AX, CW and LOY were responsible for the concept and design of the study. NG and ZW were mainly devoted to collecting and interpreting the data. LEY and JG revised it critically for important intellectual content. All authors read and approved the final manuscript.

\section{Ethics approval and consent to participate}

The study was approved by the Ethics Committee of Dongying People's Hospital (Dongying, China). Signed informed consents were obtained from the patients or the guardians.

\section{Patient consent for publication}

Not applicable.

\section{Competing interests}

The authors declare that they have no competing interests.

\section{References}

1. Friedenreich CM, Shaw E, Neilson HK and Brenner DR: Epidemiology and biology of physical activity and cancer recurrence. J Mol Med (Berl) 95: 1029-1041, 2017.

2. Benson AB III, Venook AP, Cederquist L, Chan E, Chen YJ, Cooper HS, Deming D, Engstrom PF, Enzinger PC, Fichera A, et al: Colon Cancer, version 1.2017, NCCN clinical practice guidelines in oncology. J Natl Compr Canc Netw 15: 370-398, 2017.

3. Siegel RL, Miller KD, Fedewa SA, Ahnen DJ, Meester RGS, Barzi A and Jemal A: Colorectal cancer statistics, 2017. CA Cancer J Clin 67: 177-193, 2017.

4. Wiltshire HR, Kilpatrick GJ, Tilbrook GS and Borkett KM: A placebo- and midazolam-controlled phase I single ascending-dose study evaluating the safety, pharmacokinetics, and pharmacodynamics of remimazolam (CNS 7056): Part II. Population pharmacokinetic and pharmacodynamic modeling and simulation. Anesth Analg 115: 284-296, 2012.

5. Wehrmann $\mathrm{T}$ and Triantafyllou K: Propofol sedation in gastrointestinal endoscopy: A gastroenterologist's perspective. Digestion 82: 106-109, 2010.

6. Pearlman R, Frankel WL, Swanson B, Zhao W, Yilmaz A, Miller K, Bacher J, Bigley C, Nelsen L, Goodfellow PJ, et al; Ohio Colorectal Cancer Prevention Initiative Study Group: Prevalence and spectrum of germline cancer susceptibility gene mutations among patients with early-onset colorectal cancer. JAMA Oncol 3: 464-471, 2017. 
7. Allenson K, Castillo J, San Lucas FA, Scelo G, Kim DU, Bernard V, Davis G, Kumar T, Katz M, Overman MJ, et al: High prevalence of mutant KRAS in circulating exosome-derived DNA from early-stage pancreatic cancer patients. Ann Oncol 28: 741-747, 2017.

8. Logtenberg S, Oude Rengerink K, Verhoeven CJ, Freeman LM, van den Akker E, Godfried MB, van Beek E, Borcher O, Schuitemaker N, van Woerkens E, et al: Labour pain with remifentanil patient-controlled analgesia versus epidural analgesia: A randomised equivalence trial. BJOG 124: 652-660, 2017.

9. Manjelievskaia J, Brown D, McGlynn KA, Anderson W, Shriver CD and Zhu K: Chemotherapy use and survival among young and middle-aged patients with colon cancer. JAMA Surg 152: 452-459, 2017.

10. Kaminski MF, Thomas-Gibson S, Bugajski M, Bretthauer M, Rees CJ, Dekker E, Hoff G, Jover R, Suchanek S, Ferlitsch M, et al: Performance measures for lower gastrointestinal endoscopy: A European Society of Gastrointestinal Endoscopy (ESGE) quality improvement initiative. Endoscopy 49: 378-397, 2017.

11. Bisschops R, Areia M, Coron E, Dobru D, Kaskas B, Kuvaev R, Pech O, Ragunath K, Weusten B, Familiari P, et al: Performance measures for upper gastrointestinal endoscopy: A European Society of Gastrointestinal Endoscopy quality improvement initiative. United European Gastroenterol J 4: 629-656, 2016.

12. Frölich MA, Banks C and Ness TJ: The effect of sedation on cortical activation: A randomized study comparing the effects of sedation with midazolam, propofol, and dexmedetomidine on auditory processing. Anesth Analg 124: 1603-1610, 2017.

13. Eleveld DJ, Proost JH, Vereecke H, Absalom AR, Olofsen E, Vuyk J and Struys MMRF: An allometric model of remifentanil pharmacokinetics and pharmacodynamics. Anesthesiology 126: 1005-1018, 2017
14. Kisilewicz M, Rosenberg H and Vaillancourt C: Remifentanil for procedural sedation: A systematic review of the literature. Emerg Med J 34: 294-301, 2017.

15. Porter-Stransky KA, Bentzley BS and Aston-Jones G: Individual differences in orexin-I receptor modulation of motivation for the opioid remifentanil. Addict Biol 22: 303-317, 2017.

16. Scott HB, Choi SW, Wong GTC and Irwin MG: The effect of remifentanil on propofol requirements to achieve loss of response to command vs. loss of response to pain. Anaesthesia 72: 479-487, 2017.

17. Dumans-Nizard V, Le Guen M, Sage E, Chazot T, Fischler M and Liu N: Thoracic epidural analgesia with levobupivacaine reduces remifentanil and propofol consumption evaluated by closed-loop titration guided by the bispectral index: A double-blind placebo-controlled study. Anesth Analg 125: 635-642, 2017.

18. Weiniger CF, Carvalho B, Stocki D and Einav S: Analysis of physiological respiratory variable alarm alerts among laboring women receiving remifentanil. Anesth Analg 124: 1211-1218, 2017.

19. Aaronson J, Abramovitz S, Smiley R, Tangel V and Landau R: A survey of intravenous remifentanil use for labor analgesia at academic medical centers in the United States. Anesth Analg 124: 1208-1210, 2017.

20. Shafer SL and Fisher DM: Remifentanil dosing at extremes of body weight. Anesthesiology 126: 993-994, 2017.

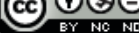

This work is licensed under a Creative Commons Attribution-NonCommercial-NoDerivatives 4.0 International (CC BY-NC-ND 4.0) License. 